This item was submitted to Loughborough's Research Repository by the author.

Items in Figshare are protected by copyright, with all rights reserved, unless otherwise indicated.

\title{
Ultra-high-net-worth individuals: self-presentation and luxury consumption on Instagram
}

\section{PLEASE CITE THE PUBLISHED VERSION}

https://doi.org/10.1108/ejm-11-2020-0853

\section{PUBLISHER}

Emerald Publishing Limited

\section{VERSION}

AM (Accepted Manuscript)

\section{PUBLISHER STATEMENT}

This paper was accepted for publication in the journal European Journal of Marketing and the definitive published version is available at https://doi.org/10.1108/ejm-11-2020-0853. This author accepted manuscript is deposited under a Creative Commons Attribution Non-commercial 4.0 International (CC BY-NC) licence. This means that anyone may distribute, adapt, and build upon the work for non-commercial purposes, subject to full attribution. If you wish to use this manuscript for commercial purposes, please contact permissions@emerald.com.

\section{LICENCE}

\section{BY-NC 4.0}

\section{REPOSITORY RECORD}

Michaelidou, Nina, George Christodoulides, and Caterina Presi. 2021. "Ultra-high-net-worth Individuals: Selfpresentation and Luxury Consumption on Instagram”. Loughborough University. https://hdl.handle.net/2134/16602023.v1. 


\title{
Ultra-high-net-worth individuals: self-presentation and luxury consumption on Instagram
}

\begin{abstract}
Purpose - Limited research has examined the segment of ultra-high-net-worth individuals (UHNWIs). This study explores how this segment self-presents with regard to luxury on Instagram.
\end{abstract}

Design/methodology/approach - We use a qualitative research approach to content-analyze 815 publicly available photos on Instagram. The analytical approach involves multiple stages and yields three key themes.

Findings - Through Instagram images, UHNWIs engage in inconspicuous consumption via subtle displays of luxury possessions and more cues that indicate luxury experiences, power, and social connections. The results further identify four dimensions of self-presentation in luxury consumption on social media: ostentatious, humble, revealed, and hidden.

Practical implications - Luxury marketers should focus on inconspicuous products and experiences that allow the UHNWIs to decelerate and spend time with their loved ones, access rare experiences, and demonstrate power via their networks.

Originality/value - We extend prior research on self-presentation on Instagram. The authors focus on UHNWIs, a neglected yet significant segment of the luxury market.

Keywords Self-presentation, Luxury consumption, Ultra-high-net-worth individuals, Instagram 


\section{Introduction}

Social media, and particularly Instagram, have enabled individuals to virtually showcase their consumption practices to others, through photos and videos, in an attempt to construct their image and identities (Grewal et al., 2019; Belk, 2013; Cadırcı and Güngör, 2019). According to Statista (2020a), there are more than 1 billion active users on Instagram, and they share 95 million photos and videos every day (Lister, 2019).

Prior research has examined the motivations that drive social media platform usage, including Instagram (Gao and Feng, 2016; Sheldon and Bryant, 2016; Sorokowska et al., 2016; Lee and Sung, 2016; Fardouly et al., 2018). These motivations include self-expression and presentation (e.g. Seidman, 2013). In particular, research suggests that individuals use photos as cues and signals to present to others their "best appearance" (e.g. ideal selves) and/or to showcase their lifestyles and experiences (Hong et al., 2020; Wallace et al., 2020). While much research exists on offline self-presentation and luxury consumption signaling (e.g. Dubois and Laurent, 1996; Cannon and Rucker, 2019; Jacob et al., 2020) scarce work has examined how individuals self-present on social media (e.g. Seidman, 2013; Chua and Chang, 2016; Hong et al., 2020) and, importantly, in relation to luxury consumption (Borel et al., 2019).

In addition, because the luxury industry, which is steadily growing (Statista, 2020b), is dependent on ultra-high-net-worth individuals (UHNWIs) (Klaus, 2021), this consumer segment is worth deeper exploration. UHNWIs consist of people that are ultrawealthy and financially elite, with a net worth in excess of US\$30 million. Currently, there are over half a million UHNWIs that account for almost one fifth of the total luxury spending (Loudenback, 2018; Knight Frank, 2020; Neate, 2020). As such, these individuals have a disproportionately large impact on the luxury industry (Northrop \& Johnshon, 2020b). For some luxury sectors, such as yachts and private aviation, UHNWIs represent the sole target market because such products/services allow these individuals to achieve recognition, uniqueness, and individuality 
and to further widen the gap between themselves and their peers (Atwal and Bryson, 2017). Currently, research examining how UHNWI consumers represent themselves on social media is nonexistent. Indeed, we know very little about UHNWIs in relation to their luxury consumption because they are an exclusive niche of individuals who do not typically participate in research. To address this gap, we conduct a study that aims to answer the following research question: How do UHNWIs self-present on Instagram in relation to luxury consumption?

To address the research question, we utilize an inductive methodology whereby we collect and content-analyze 815 photographs and textual stories posted publicly on Instagram by 33 UHNWIs. Our analysis yields insightful results that contribute to theory and practice. We use Instagram, as opposed to other social media platforms, because Instagram is a dedicated photo-sharing site (Hong et al., 2020) that is used by UHNWIs (Northrop \& Johnson, 2020a).

The contribution of this study is twofold: First, in terms of theoretical contribution, this study fills a key gap in the literature about self-presentation on social media - and importantly, in the context of UHNWIs. This study is the first to examine how individuals in this segment present themselves and their luxury consumption on Instagram, thus yielding novel knowledge about this significant segment of ultrawealthy consumers. We identify four dimensions of selfpresentation, thus expanding existing knowledge on the nature of this concept in relation to luxury consumption. Second, the study offers important practical insights, in the form of specific guidelines and tactics for luxury marketers who target UHNWIs.

In the following section, we present the theoretical background of the study, which draws on the concept of self-presentation, followed by a discussion of luxury consumption. Subsequently, we present our methodological approach and offer a discussion of the key findings and their implications for practice. We conclude with a discussion of the study's limitations and directions for further research. 


\section{Theoretical Background}

\subsection{Self-presentation on social media}

Self-presentation is a goal-directed and highly selective activity, whereby individuals control information "to create desirable impressions on audiences" (Schlenker and Wowra, 2003, p. 879). The concept differs from that of self-disclosure, which denotes individuals communicating "factual representations of self" irrespective of the impact on public image (Johnson, 1981; Schlosser, 2020). Several authors have argued that the principles of selfpresentation, which stem from the work of Goffman (1959), apply to online environments such as social media platforms, as these contexts allow users to assume or present different selves and identities through visual representations (e.g. photos, selfies) (Chua and Chang, 2016; Leary and Kowalski, 1990; Cadırcı and Güngör, 2016; Bullingham and Vasconcelos, 2013; Hong et al., 2020).

The "ecosystem" of social media allows users to present "versions" of themselves to manage impressions and self-presentations. Schlosser (2020) explains that social media platforms provide individuals with a multitude of possibilities regarding how to present themselves and their material wealth, due to the asynchronous communication, the existence of multiple audiences, and the opportunity for feedback. Specifically, and relative to face-toface communication, social media communication is largely asynchronous (Ellison et al., 2006), giving individuals the ability to "shape" their self-presentation on these platforms in a strategic and controlled manner to present their "best self" or different versions of themselves (Hong et al., 2020; Jang et al., 2015).

In addition, because multiple audiences exist on social media, who are recipients of the intended communication, individuals attempt to manage impressions in terms of what to post and what to discuss (e.g. holidays vs politics). Indeed, the number and the composition of social 
media audiences influence individuals' self-presentation (Schlosser, 2020). For instance, one's social media audience may consist of peers (e.g. homogenous audiences) or may comprise a diverse group of individuals, thus triggering different forms of self-presentation. Concurrently, social media's ability to elicit feedback enhances the urge to self-present, in that individuals attempt to "please audiences" by presenting themselves in a way that meets their expectations (Chua and Chang, 2016; Seidman, 2013; Schlosser, 2020).

A large stream of research has focused on examining why individuals self-present on social media platforms (e.g. via photos and selfies), positing that self-presentation is linked to motives such as self-validation and approval, as well as personality traits such as narcissism and extraversion (Seidman, 2013; Sorokowska et al., 2016; Etgar and Amichai-Hamburger, 2017; Igani and Schroeder, 2016). Adding to this stream, scholars have argued that nonverbal elements in photos and selfies, including representations of socioeconomic status, mood, and appearance, operate as cues of self-presentation on social media, thus allowing individuals to enact different self-identities (Hong et al., 2020). For instance, prior research on selfpresentation on Twitter indicates that female athletes tend to use artistic and scenic pictures, focusing on their nonathletic, casual, and glamorous appearances as opposed to their athletic self (Li et al., 2017; Coche, 2014). Similarly, Leban et al.'s (2020) work on high-net-worth (HNW) social media influencers suggests that these individuals self-present on Instagram in different ways by enacting different personas, such as ambassadors of true luxury, good role models, and altruists. Interestingly, the authors find that HNW influencers tend to be inconspicuous in their consumption of luxury, focusing instead on meaningful, tasteful, and sustainable luxury activities and settings. In addition, the authors find that these individuals do not adopt a materialistic approach to luxury but rather focus on luxury and leisure experiences (vs possessions) that allow them to enjoy life (Leban et al., 2020). 


\subsection{Luxury consumption}

The growing body of research on luxury suggests that the concept of luxury is subjective, relative, and context-specific (e.g. Ko et al., 2019; Turunen, 2018), making it difficult for researchers to arrive at an agreed-upon definition of what constitutes a luxury product. According to Tynan et al. (2010, p. 1158), luxury in a consumption setting refers to "high quality, expensive and non-essential products and services that appear to be rare, exclusive, prestigious, and authentic and offer high levels of symbolic and emotional/hedonic values through customer experiences". The conceptualizations of luxury in the pertinent literature vary in terms of the specific expressions or sources of luxury value, which include, inter alia, uniqueness (e.g. Stathopoulou and Balabanis, 2019; Parguel et al., 2016; Vigneron and Johnson, 2004), aesthetics (e.g. Hudders et al., 2013; de Barnier et al., 2012), excellent quality (e.g. Stathopoulou and Balabanis, 2019; Christodoulides et al., 2009), heritage/history (e.g. Roux et al., 2017; de Barnier et al., 2012), elitism and distinction (e.g. Dubois et al., 2001; Kapferer, 1998), conspicuousness (e.g. Amatulli et al., 2018; Wiedmann et al., 2009), and hedonic escapism (Holmqvist et al., 2020). However, researchers generally agree that what differentiates luxury and nonluxury products is the mix of their components on three dimensions: functionalism, experientialism, and symbolic interactionism (Berthon et al., 2009; Shukla et al., 2015).

With the increasing "democratization of luxury" due to globalization and a growing demand for prestige products and services at affordable prices (Kapferer and Bastien, 2012), alternative conceptualizations of luxury have emerged. These include "masstige" (Kumar et al., 2020; Paul, 2015), unconventional luxury (Thomsen et al., 2020; Rosenbaum et al., 2019), and collaborative luxury consumption (Pantano and Stylos, 2020), which challenge key characteristics of traditional luxury, such as being expensive and exclusive. Despite the concept of luxury expanding to include "day trippers" (or excursionists) - that is, the bottom end of the 
wealth pyramid - there is a paucity of research on the concept of luxury and what it means for the top of the wealth pyramid, that is, the ultrawealthy.

According to the literature, luxury consumption is driven by two motives: personal (intrinsic) and interpersonal (extrinsic) (Theodoridis and Vassou, 2018). Personal motives typically focus on the hedonic value of luxury, which represents access to pleasure through luxury's multisensorial compression, and perfectionism (pursuing high standards for oneselfin this case, via consumption), which is reflected in luxury products' superior quality, craftmanship, and refinement. Extrinsic motives focus on the role of luxury as a social marker that recreates social stratification in capitalist societies and allows consumers to achieve social elevation (Kapferer and Bastien, 2012). The preference for more expensive over cheaper products that are nonetheless functionally similar is, according to Nelissen and Meijers (2011), often attributed to "conspicuous consumption", a term originally coined by Veblen (1899) to explain individuals' "tendency to enhance their image through overt consumption of possessions, which communicates status to the others" (O'Cass and McEwen, 2004, p. 34). Luxury products are symbols of one's success, and as such, their public display enhances one's social status and cachet.

While conspicuous luxury consumption focuses on ostentation and signaling to convey wealth, impress others, and confirm social status (Corneo and Jeanne, 1997), there are variations that are mainly attributed to two underlying factors: the "bandwagon effect" and "snob effect". Due to their strong symbolic meanings, luxury products can instill a sense of affiliation with other consumers or help differentiate consumers from other consumers (Kastanakis and Balabanis, 2012; 2014; Leibenstein, 1950). Therefore, some consumers use luxury products and brands in a relational pattern to integrate socially with groups of consumers who publicly display them. Other consumers seek to consume rare, novel, or stealth luxuries 
in a contrast-creating pattern to distance themselves from other consumers and thereby satisfy their need for uniqueness (Kastanakis and Balabanis, 2014).

Han et al. (2010) identify two clusters of consumers, both possessors of significant wealth, who nonetheless exhibit different conspicuous consumption behaviors due to their varying need for status. Parvenus have a high need for status, and their consumption of luxury products aims primarily to dissociate them from lower-wealth groups and associate them with higher-wealth groups. To this end, parvenus consume established brand names and visible logos, which act as loud signals that are broadly recognizable across consumer segments. Patricians are more concerned with their in-group affiliation and exhibit discretion in their luxury consumption via more subtle signals (Berger and Ward, 2010), niche brands, and bespoke products that are only recognized by connoisseurs - in this case, their fellow patricians.

Consistently, Eckhardt et al. (2015) argue for the decoupling of the luxury construct from conspicuousness and a shift toward inconspicuous consumption characterized by "use of subtly marked products which are misrecognized by most observers, but facilitate interaction with those who have the requisite cultural capital to decode the subtle signals" (p. 808). This articulation is consistent with the ideas of Bourdieu (1984), according to whom the petite bourgeoisie (e.g. parvenus) exhibit a lifestyle that reflects an aspiration to a bourgeoisie lifestyle (e.g. patricians) but insufficient cultural capital to attain it. Despite their wealth, members of the petite bourgeoisie adopt "popularized" tastes and aesthetic forms due to their lack of cultural capital. Cultural capital does not exist in isolation but interacts with economic and social capital to determine one's position in the social hierarchy (Bourdieu, 1984).

While traditionally the focus of conspicuousness has been on the possession and display of material goods, a recent stream of literature highlights the importance of the luxury experience (Klaus 2020; de Kerviler and Rodriguez, 2019). Through a process of self- 
expansion, luxury experiences offer consumers "opportunities to learn, acquire skills, and engage in rich emotional or sensorial discoveries", ultimately leading to an enriched selfconcept (de Kerviler and Rodriguez, 2019, p. 251). A recent report by McKinsey (2020) highlights the increasing importance of experiential luxury-which includes, inter alia, upscale hotels, resorts, cruises, and restaurants — as one of the most dynamic and fast-growing sectors of luxury. Interestingly, millennials and, to a lesser degree, baby boomers now focus more on luxury experiences and "Instagrammable moments" rather than on status goods (McKinsey 2020). This trend is in line with previous research showing that experiences bring greater happiness than material possessions (Nicolao et al., 2009), particularly extraordinary experiences that are uncommon and infrequent and transcend the (ordinary) experiences of everyday life (Bhattacharjee and Mogilner, 2014). By sharing pictures of such luxury experiences on Instagram, consumers compensate for the fact that the consumption of these experiences is typically less conspicuous than that of luxury goods (Luna-Cortés, 2017).

Another stream of literature seeks to diminish the role of possessions and public exposure of status symbols by focusing on individuals' social interactions (Goffman, 1967). This literature suggests that status manifests through tacit assessments in everyday social interactions, as these involve "micro-political acts of status claiming" that allow individuals to (re)negotiate their societal roles and positions (Dion and Borraz, 2017, p.2). Thus, the focus is no longer on the ownership and display of goods that signal status but rather on the status battle that emerges from social interactions.

Shifting the focus of conspicuousness from the preciousness and scarcity of products to the preciousness and scarcity of individuals, Bellezza et al. (2017) suggest that long hours of work and lack of leisure time have become powerful status symbols signaling that the individuals concerned are valued and in demand. By contrast, Husemann and Eckhardt (2019) argue that rather than busyness and lack of leisure time, a new status symbol is deceleration- 
a concept that refers to a slower experience of time. According to Husemann and Eckhardt (2019, p. 1161), people in contemporary societies work excessively and are short of time, so "only a fortunate few can afford to escape to oases of deceleration".

\section{Methodology}

\subsection{Sampling and data collection}

In this study, we explore how UHNWIs present themselves with respect to luxury on Instagram. Therefore, our first concern was to identify Instagram accounts of UHNWIs. In the absence of a list of UHNWIs, we considered the available alternatives. The Sunday Times "Rich List 2020" (https://www.thetimes.co.uk/sunday-times-rich-list) was discarded because it included only UK residents and therefore was not consistent with Instagram's worldwide population, nor with the fact that the United States, China, and Japan have more millionaires than the United Kingdom (McCarthy, 2019). The "Web Rich List" from the BBC (http://news.bbc.co.uk/1/hi/technology/8562379.stm) was appealing because the Internet has created some of the youngest billionaires and digital natives who are more familiar with Instagram (Statista, 2020a). However, limiting our attention to a specific sector would have limited the representativeness of the UHNWIs diverse sources of wealth (e.g. family, inherited wealth). Therefore, we used the publicly available Forbes 2020 "World's Billionaires List" (https://www.forbes.com/billionaires/) as a sampling frame to identify UHNWIs because of the list's reputation, its widespread recognition, and its international composition. The full list includes 2,095 individuals. Their wealth ranges from $\$ 113$ billion to $\$ 1$ billion, they range in age from 22 to 101 years, and most are male. We included only official and public accounts (verified with the blue tick). There were a total of 33 official, and public accounts in the sample. 


\subsection{Images selection}

Some accounts were active, while others had only a few images. All accounts included some comments, but none included replies to the comments. Selected content gave a fair representation of the individual stream in terms of subject and style while capturing the variation across accounts (maximum variation sampling). This sampling yields "(1) highquality, detailed descriptions of each case, which are useful for documenting uniqueness, and (2) important shared patterns that cut across cases and derive their significance from having emerged out of heterogeneity" (Patton, 2002, p. 235). For example, if a stream included luxury experiences or possessions photos, we would include this in the sample, but we would not include 20 photos if there were different types of content in the stream. At the same time, if, in our exploration, we noted different types of photos, we would include an exemplar of categories.

The final sample, which contained 815 images, provides an overview of the types of images that can be found in UHNWIs' (i.e. billionaires') official Instagram accounts. Confidence in the qualitative value of our sample was bolstered insofar as we could observe repetition in the types of content we collected across the various accounts, which provided reassurance that extending the sample further would not result in significantly new images (i.e. we had achieved an acceptable degree of data saturation) (Suri, 2011).

\section{Analysis}

We approached the UHNWIs' photos on Instagram as rich visual texts (Gleeson, 2011). We adopted a visual analysis process similar to that used in Presi et al. (2016) to analyze brand selfies. We started with the descriptive analysis of the content. Through objective descriptions of the images, we documented the type of content that was shared, that is, the material reality shown in the photos. Then, using the constant comparative method (Glaser and Strauss, 1968), 
we identified the categories of images that could be found in these accounts. The team met to discuss the initial categories (e.g. luxury experiences, possessions etc.) on two occasions.

Next, the researcher leading the analysis conducted a formal analysis of the content. At this stage, principles of photographic compositions were used to explain how the visual elements deliver the image meaning (Ang, 2006). These include elements such as objects, colors, composition, and dominance and subordinance of the subjects, among others. The formal analysis shows how the image communicates through its composition, not just what it captures. Formal analysis helps explain why an image, which includes similar visual elements, may evoke a different response. In other words, we applied the semiotic principle of relationality to unpack how visual elements come together into particular kinds of messages (Goodings and Brown, 2011).

Third, we conducted polytextual thematic analysis of the UHNWIs' Instagram cultural space. This type of analysis assumes that texts can only be read in reference to other texts (Gleeson, 2011). Therefore, we considered the images along with the meaning of all the elements that they included (e.g. brands, consumption experiences, celebrities). Through a process of categorization and abstraction, as explained by Spiggle (1994), we identify the repetitive features, or themes, that underlie how UHNWIs display themselves on Instagram. This iterative process continued until no further distinctive themes emerged. Team discussions also helped refine the selection. A summary of the codes and themes discovered and examples of images can be found in Appendix 1.

\section{Findings}

In this study, we explore the self-presentation practices of UHNWIs on Instagram. The images offer a glimpse into their lifestyles and consumption practices. Three key themes 
emerge: display of luxury possessions, consumption of time, and power styles and resources. We discuss each in turn.

\subsection{Display of luxury possessions}

There seems to be a lot of variation in terms of how much luxury is on display. Obvious displays of possessions (e.g. luxury cars, beautiful houses) and brands (e.g. Dior) can be found, but this is only a superficial reading of the photos. Luxury possessions are exposed organically and indirectly in the background of the photos rather than being the central focus of the image. For example, the private jet appears in a photo, but the photo is about the fact that the UHNWI is bringing his best friend (the dog) with him on a trip. Therefore, while there is conspicuous consumption of luxury, its display is controlled and often indirect.

\subsection{Consumption of time}

The autobiographical nature of Instagram lends itself to revealing how UHNWIs spend their time and therefore their lifestyle. The photos collectively provide a glimpse into their life at work, at home, on holiday, socializing, and exercising. The variety and frequency of the images suggest busy but balanced lifestyles. Time at work is often presented with cues such as business attire and/or accompanying text that celebrates hard work to achieve results. At the same time, there are holiday photos, downtime spent with families, and having fun with business associates. There are no photos of stressful meetings or a difficult day at the office. Effort is shown only to a small extent; the accounts reproduce celebrations of the results: the good life, both personally and professionally.

A common denominator throughout the photos and accompanying text is that of making experiences tangible (Lyu, 2016). Daily life is embedded in these Instagram images. The UHNWIs' lifestyles are aspirational for their professional and personal success as well as the suggested balance between them. The images are also aspirational because these UHNWIs can 
spend their time doing things that not everyone can. The analysis discloses the following luxury experiences:

- Luxurious locations. Experiences can be luxurious because of where they take place, such as a breathtaking view from a hotel room window or formal events in luxurious surroundings. Photos can be carefully framed, giving the viewer the opportunity to experience this indirectly. Other photos are not crafted to share the experience with the viewer, but rather to show it off. Multiple luxury cues are included such as elegant clothes, chandeliers or the long corridor of the luxury hotel, to show off the environment in which it was taken.

- Privileged access location. Some experiences may occur in not obviously luxurious places, but access to them reveals privilege. For example, access to a chef's kitchen, can be a luxury experience that not many can have.

- Involvement in extraordinary experiences. Some experiences, because of their nature, are accessible to only the very few. These are leading-edge projects or endeavors; being able to contribute to them sets the person apart from others, even if they do not experience them directly themselves. For example, the privilege of being able to be involved in extraordinary activities that only UHNWIs can afford. Photos show an upclose view of the experience, which suggests that the UHNWI is not a mere spectator but rather is experiencing it from the inside and, in so doing, is part of it.

- Celebrity events. These are aspirational events that, due to their public nature, combine privileged access, luxury surroundings, high-class dress codes, and an audience. Invitations to these events symbolize status and "being in demand". The accounts show photos filled with celebrity codes: the red carpet, the formal attire, walking and smiling for the photographers. It is clear that the UHNWIs belong to it as any other celebrity does. 


\subsection{Power styles and resources}

Another dominant narrative throughout the accounts is one of power. UHNWIs are powerful, but how power is presented varies and so do the sources of power in the images. On the one hand, we find images that communicate power in masculine and individualistic terms. Images of leadership, such as addressing a crowd or employees, are common. Images display physical strength and metaphors of dominance such as portraying a lion. On the other hand, soft power is also represented. Here, the emphasis is on prosocial behavior, or having power to make a difference or support a cause. Examples depict a collaborative leadership style via friendly images with employees and endorsements of friends' business endeavors.

In terms of resources, social capital, which is exemplified in connections with important people in politics or popular culture, is prevalent throughout. UHNWIs are well-liked and connected. Indeed, this is a striking feature in most of the accounts. Sontag (1977) describes photographs as surrogates for possession, and in this sense, influential relationships become "luxury products" by virtue of their exclusivity, prestige, and ability to communicate power to others. Reference to economic power is shown largely indirectly, as discussed in the previous themes, although a limited number of images referencing money and wealth in an ostentatious manner can also be found, such as sitting on a throne made of money. UHNWIs differ also in terms of their taste and how they display it. On the one hand, we have those who show affiliation with the upper class by exhibiting refined taste (Bourdieu, 1984) through, for example, their passion for art, or through sophisticated aesthetics as revealed in their homes. On the other hand, the display may be more direct . Indeed, there are images reflecting power beyond classic muscular beauty such as ancient and classic statues appropriated for personal display and paired with modern items. 
To conclude this section, we use the semiotic square to both summarize and systematize the foregoing analysis (see Figure 1). We identify four distinct and interrelated dimensions of self-presentation in UHNWIs' Instagram profiles in relation to luxury: ostentations, humble, revealed and hidden. "Ostentatious" display is obvious and often irreverent diplay of luxury. This form of self presentation includes the explicit display of luxury as well as showing off social connections or money. The UHNWIs diplay their exceptional lifestyles in this way. This dimension is in clear contrast with "Humble" diplays, which downplay luxury via ordinary life narratives and repaying for priviledge by making positive impact on society. "Ostentatious" and "Humble" displays are related through a relationship of contrariety of superiority, the former emphases the economic and/or social superiority of the UHNWI while the latter down plays it or balances it via pro-social behaviour. The third type of self-presentation is "Hidden". This display is characterised by the lack of branding (unless part of the individial's business interests) and the omission of elements of luxury. It also points to what is not seen, for example there is no reference to the cost or negative aspects of luxury; there is no conversation in the comments, no reply to them. Both "Hidden" and "Humble" displays are forms of restrained self-presentation practices. "Hidden" and "Ostentatious" displays are related through contradiction of disclosure, the former is an obvious non-disclosure, the latter is showing off. The fourth form of display is "Revealed". This is an indirect and perhaps even unintentional form of self-presentation through luxury. Luxury can be seen but is not the main focus of the image, for example it appears in the background. "Revealed" and "Ostentatous" diplays both show affluence but in different and complementary ways. "Revealed" display is in contradiction with the "humble" one on the basis of control: the former is the lack of control through indirect display, the latter is about controlled self-presentation. Finally, the "Revealed" display, which points to some transparency of the Instagram profiles, is in contrary relationship with the "Hidden" display which is about omitting cues from view. 
Figure 1 here.

\section{Discussion, Contributions, and Implications}

We build on the work of Hong et al. (2020) on self-presentation on Instagram by focusing on the luxury consumption of UHNWIs. The results reveal that UHNWIs' selfpresentation with respect to luxury consumption is a diverse and complex field. Different selfpresentation dimensions can be identified and each one relates to the others in an opposing or complementary manner; suggesting that while Instagram may be a window into the luxurious life of the UHNWIs, the images posted provide different views to the followers.

More specifically, we identify four dimensions of UHNWIs' self-presentation in relation to luxury consumption: (1) ostentatious, (2) humble, (3) revealed, and (4) hidden. Examining these dimensions suggests that UHNWIs generally present themselves in a less conspicuous and more indirect manner (Leban et al., 2020), showing more experiences and social interactions that communicate power, exclusivity, and status (Sontag, 1977; Dion and Borraz, 2017). Luxury consumption is reflected via the subtle display of luxury possessions; consumption of time (Husemann and Eckhardt, 2019), which includes luxury experiences at exclusive locations (de Kerviler and Rodriguez, 2019) and passing time attending aspirational events; and influential relationships that emphasize prestige (Dion and Borraz, 2017). Overall, these dimensions interact to help UHNWIs shape and control their image and specific aspects of it (e.g. identities) on Instagram.

\subsection{Theoretical contributions}

Our research offers several theoretical contributions. First, and in relation to our research question this study fills a significant research gap by examining UHNWIs' selfpresentation on Instagram in relation to luxury consumption, which reflects a topic that has not 
been examined before in the extant literature. Importantly, we identify four dimensions that exemplify how UHNWIs self-present, thus expanding current understanding on how this segment strategically shapes information with regard to their luxury consumption. A second contribution pertains to the focus of this study on UHNWIs, a very exclusive segment of the market who have not been the focus of research on luxury consumption to date, even though they constitute a key segment of the luxury industry. Finally, the study also contributes to research on the domain of luxury consumption, by highlighting how power, consumption of time, and social interactions intertwine in luxury consumption, reinforcing the idea that highstatus individuals consume luxury inconspicuously (Rucker and Galinsky, 2009).

\subsection{Managerial implications}

Our findings regarding UHNWIs have significant managerial implications. UHNWIs' Instagram account is a tool that they use for impression management and arguably does not capture their lifestyle in its entirety. However, managers can still design actionable strategies. By observing their public profiles on Instagram, marketers interested in this segment may categorize them along the dimensions of self-presentation vis-à-vis luxury identified in this study (i.e., ostentatious, humble, hidden and revealed) and use these insights to inform their communication strategies. In targeting these important individuals, managers should recognize that most UHNWIs do not want to flaunt their wealth to the general public and instead prefer to be seen consuming experiences rather than possessions. While this does not mean that these individuals do not also consume possessions, they are less likely to consume them publicly on their social media accounts. Possessions are probably more comfortably shared with their fellow patricians or members of their closed network. Instead, extraordinary experiences are perceived to be less ostentatious and more humble, thus putting UHNWIs more at ease when it comes to signaling these on Instagram. 
Another implication is related to "who UHNWIs know", as it is suggested that these individuals also derive status from other powerful individuals in their network. Managers could highlight these connections and networking opportunities in their communications with UHNWIs. For example, they might mention that cultural, political, and economic elites patronize or are members of specific exclusive retreats and private clubs. This would be particularly effective for parvenus, who aspire to associate with patricians. Finally, managers should acknowledge how busy these individuals are and target them with products such as private jets and helicopters that help them save time and better manage their busy schedules; at the same time, they should target UHNWIs with products that help them decelerate and appreciate time with their families and loved ones, such as a luxury yacht or a cruise.

\subsection{Limitations and directions for further research}

No research is free of limitations, and the present study is no exception. In the absence of a robust sampling frame that captures UHNWIs, defined as having a net worth of at least \$30 million, our study employed the Forbes "World's Billionaires List", thus focusing on billionaires who comprise the top end of this segment. Further research might examine the lower and middle ends of the UHNWI spectrum, particularly those who have recently achieved this status, to observe and juxtapose their self-presentation and luxury consumption on Instagram with the upper end of the segment to determine if the themes identified are uniform across this segment. In addition, our unit of analysis was the photo posted by the UHNWI rather than the UHNWI himself or herself. Further research might explicitly consider the overall profile of each UHNWI and their holistic approach to posting with a view to developing a typology of UHNWIs based on the way they self-present and portray their luxury consumption. Having said this, we observe that individual profiles are not necessarily internally homogenous with respect to self-presentation in luxury consumption, so our approach is 
arguably more comprehensive because it does not lose any information through aggregation. Our study adopts an inductive approach to identify themes related to UHNWIs' selfpresentation on Instagram. Other research could adopt a quantitative approach to identify drivers of the various themes, such as wealth size, old versus new money, age, and gender. Finally, with a larger sample of photos, generated under a different sampling frame that would also include lower- and middle-end UHNWIs, it would be possible to compare and contrast self-presentation practices of UHNWIs from different regions and cultural backgrounds, particularly with regard to their luxury consumption. 


\section{References}

Amatulli, C., Angelis, M.D., Korschun, D. and Romani, S. (2018), “Consumers perceptions of luxury brands' CSR initiatives: an investigation of the role of status and conspicuous consumption”, Journal of Cleaner Production, Vol. 194, pp. 277-287.

Ang, T. (2006), Digital Photographer's Handbook, DK Publishing, London.

Atwal, G. and Bryson, D. (2017), Luxury brands in China and India, Macmillan Publishers, London.

Belk, R.W. (2013), "Extended self in a digital world”, Journal of Consumer Research, Vol. 40 No. 3, pp. 477-500.

Bellezza, S., Neeru P. and Keinan, A. (2017), "Conspicuous consumption of time: when busyness and lack of leisure time become a status symbol," Journal of Consumer Research, Vol. 44 No. 1, pp. 118-138.

Berger, J. and Ward, M. (2010), "Subtle signals of inconspicuous consumption”, Journal of Consumer Research, Vol. 37 No. 4, pp. 555-569.

Berthon, P.R., Pitt, L., Parent, M. and Berthon, J-P. (2009), “Aesthetics and ephemerality: observing and preserving the luxury brand", California Management Review, Vol. 52 No. 1, pp. 45-66.

Bhattacharjee, A. and Mogilner, C. (2014), "Happiness from ordinary and extraordinary experiences", Journal of Consumer Research, Vol. 41 No. 1, pp. 1-17.

Borel, L., Christodoulides, G. and Stathopoulou, A. (2019), “\#Me and my luxury brands: a model of drivers and outcomes of luxury brand selfies", AMS World Marketing Congress, Edinburgh. 
Bourdieu, P. (1984), Distinction: a social critique of the Judgement of taste, Routledge, London.

Bullingham, L. and Vasconcelos, A.C. (2013), "The presentation of self in the online world: Goffman and the study of online identities”, Journal of Information Science, Vol. 39 No. 1, pp. 101-112.

Cadırc1, T.O. and Güngör, A.S. (2019), "Love my selfie: selfies in managing impressions on social networks", Journal of Marketing Communications, Vol. 25 No. 2, pp. 268-287.

Cannon, C. and Rucker, D.D. (2019), “The dark side of luxury: social costs of luxury consumption", Personality and Social Psychology Bulletin, Vol. 45 No. 5. doi.org/10.1177/0146167218796790.

Christodoulides, G., Michaelidou, N. and Li, C.H. (2009), "Measuring perceived brand luxury: an evaluation of the BLI scale", Journal of Brand Management, Vol. 16 No. 5/6, pp. 395-405.

Chua T.H.H. and Chang L. (2016), "Follow me and like my beautiful selfies: Singapore teenage girls' engagement in self-presentation and peer comparison on social media", Computers in Human Behavior, Vol. 55, pp. 190-197.

Coche, R. (2014), "How golfers and tennis players frame themselves: a content analysis of twitter profile pictures", Journal of Sports Media, Vol. 9 No. 1, pp. 95-121.

Corneo, G. and Jeanne, O. (1997), "Conspicuous consumption, snobbism and conformism”, Journal of Public Economics, Vol. 66 No. 1, pp. 55-71.

de Barnier, V., Falcy, S. and Valette-Florence, P. (2012), "Do consumers perceive three levels of luxury? A comparison of accessible, intermediate, and inaccessible luxury brands", Journal of Brand Management, Vol. 19 No. 7, pp. 623-636. 
de Kerviler, G. and Rodriguez, C.M. (2019), "Luxury brand experiences and relationship quality for millennials: the role of self-expansion", Journal of Business Research, Vol. 102, pp. 250-262.

Dion, D. and Borraz, S. (2017), "Managing status: how luxury brands shape class subjectivities in the service encounter", Journal of Marketing, Vol. 81 No. 5, pp. 67-85.

Dubois, B. and Laurent, G. (1996), "The functions of luxury: a situational approach to excursionism", in Corfman, K.P. and Lynch, J.G., Jr. (Eds.), NA - Advances in Consumer Research, Vol. 23, Association for Consumer Research, Provo, UT, pp. 470-477.

Dubois, B., Laurent, G. and Czellar, S. (2001), “Consumer rapport to luxury: analyzing complex and ambivalent attitudes", HEC, Jouy en Josas, France. Consumer research working paper no. 736 .

Eckhardt, G.M., Belk, R.W. and Wilson, J.A.J. (2015), “The rise of inconspicuous consumption”, Journal of Marketing Management, Vol. 31 No. 7/8, pp. 807-826.

Ellison, N., Heino, R. and Gibbs J. (2006), “Managing impressions online: self-presentation processes in the online dating environment", Journal of Computer Mediated Communication, Vol. 11, pp. 415-441.

Etgar, S. and Amichai-Hamburger, Y. (2017), "Not all selfies took alike: distinct selfie motivations are related to different personality characteristics", Frontiers in Psychology, Vol. 8, pp. 842.

Fardouly, J., Willburger, B.K. and Vartanian, L.R. (2018), “Instagram use and young women's body image concerns and self-objectification: testing mediational pathways", New Media \& Society, Vol. 20 No. 4, pp. 1380-1395. 
Gao, Q. and Feng, C. (2016), "Branding with social media: user gratifications, usage patterns, and brand message content strategies", Computers in Human Behavior, Vol. 63, pp. 868890.

Glaser, B. and Strauss, A. (1968), The discovery of grounded theory: strategies for qualitative research, Aldine, Chicago, IL.

Gleeson, K. (2011), "Polytextual thematic analysis for visual data: pinning down the analytic", in Reavey, P. (Ed.), Visual Methods in Psychology, Psychology Press, New York, pp. 314-329.

Goffman, E. (1959), The presentation of self in everyday life, Doubleday-Anchor, Garden City, NY.

Goffman, E. (1967), Interaction ritual, Aldine, Oxford, UK.

Goodings, L. and Brown, S.D. (2011), “Textuality and visuality in Myspace communication", in Reavey, P. (Ed.), Visual Methods in Psychology, Psychology Press, New York, pp. 87-102.

Grewal, L., Stephen, A.T. and Coleman, N.V. (2019), "When posting about products on social media backfires: the negative effects of consumer identity signaling on product interest", Journal of Marketing Research, Vol. 56 No. 2, pp. 197-210.

Han, Y.J., Nunes, J.C. and Drèze, X. (2010), "Signaling status with luxury goods: the role of brand prominence", Journal of Marketing, Vol. 74, pp. 15-30.

Holmqvist, J. Ruiz, C.D. and Peñaloza, L. (2020), "Moments of luxury: hedonic escapism as a luxury experience", Journal of Business Research, Vol. 116, pp. 503-513. 
Hong, S., Jahng, M.R., Lee, N. and Wise, K.R. (2020), "Do you filter who you are? Excessive self-presentation, social cues, and user evaluations of Instagram selfies", Computers in Human Behavior, Vol. 104, doi:10.1016/j.chb.2019.106159.

Hudders, L., Pandelaere, M. and Vyncke, P. (2013), "Consumer meaning making: the meaning of luxury brands in a democratised luxury world", International Journal of Market Research, Vol. 55 No. 3, pp. 391-412.

Husemann, K.C. and Eckhardt, G.M. (2019), “Consumer deceleration”, Journal of Consumer Research, Vol. 45 No. 6, pp. 1142-1163.

Iqani, M. and Schroeder, J.E. (2016), “\#selfie: digital self-portraits as commodity form and consumption practice”, Consumption Markets \& Culture, Vol. 19 No. 5, pp. 405-415.

Jacob, I., Khanna, M. and Rai, K.A. (2020), “Attribution analysis of luxury brands: an investigation into consumer-brand congruence through conspicuous consumption”, Journal of Business Research, Vol. 116, pp. 597-607.

Jang, J.Y., Han, K., Shih, P.C. and Lee, D. (2015), “Generation like: comparative characteristics in Instagram", ACM conference on human factors in computing systems (CHI), doi.org/10.1145/2702123.2702555.

Johnson, J.A. (1981), “The ‘self-disclosure' and 'self-presentation' views of item response dynamics and personality scale validity”, Journal of Personality and Social Psychology, Vol. 40, pp. 761-769.

Kapferer, J-N. (1998), ‘Why are we seduced by luxury brands?’ Journal of Brand Management, Vol. 6 No. 1, pp. 44-49.

Kapferer, J. and Bastien, V. (2012), The luxury strategy: break the rules of marketing to build luxury brands, 2nd ed. Kogan, Philadelphia, PA. 
Kastanakis, M.N. and Balabanis, G. (2012), "Between the mass and the class: antecedents of the 'bandwagon' luxury consumption behavior", Journal of Business Research, Vol. 65 No. 10, pp. 1399-1407.

Kastanakis, M.N. and Balabanis, G. (2014), "Explaining variation in conspicuous luxury consumption: an individual differences' perspective", Journal of Business Research, Vol. 67 No. 10, pp. 2147-2154.

Klaus, P. (2020), "The end of the world as we know it? The influence of online channels on the luxury customer", Journal of Retailing and Consumer Services, Vol. 57, pp. 1-7.

Klaus, P. (2021), “What Matters Most to Ultra-High-Net-Worth Individuals? Exploring the UHNWI Luxury Customer Experience (ULCX)"Journal of Product \& Brand Management, (in press).

Knight Frank. (2020), The wealth report, https://www.knightfrank.com/wealthreport, (accessed 29 October 2020).

Ko, E., Costello, J.P. and Taylor, C.R. (2019), "What is a luxury brand? A new definition and review of the literature", Journal of Business Research, Vol. 99, pp. 405-413.

Kumar, A., Paul, J. and Unnithan, A.B. (2020), “"Masstige' marketing: a review, synthesis and research agenda", Journal of Business Research, Vol. 113, pp. 384-398.

Leary, M.R. and Kowalski, R.M. (1990), "Impression management: a literature review and two-component model", Psychological Bulletin, Vol. 107 No., pp. 34-47.

Leban, M., Thomsen, T.U., von Wallpach, S., Benjamin, G. and Voyer, B.G. (2020), “Constructing personas: how high-net-worth social media influencers reconcile ethicality and living a luxury lifestyle", Journal of Business Ethics, https://doi.org/10.1007/s10551$\underline{020-04485-6 .}$ 
Lee, J-A. and Sung, Y. (2016), "Hide-and-seek: narcissism and 'selfie'-related behavior", Cyberpsychology, Behavior, and Social Networking, Vol. 19 No. 5, .pp. 347-351.

Leibenstein, H. (1950), “Bandwagon, snob, and Veblen effects in the theory of consumers' demand", Quarterly Journal of Economics, Vol. 64 No. 2, pp. 183-207.

Li, B., Stokowski, S., Dittmore, S.W. and Rolfe, D.T. (2017), “A case study of selfrepresentation on Twitter: a gender analysis of how student-athletes portray themselves", Global Sport Business Journal, Vol. 5 No. 1, pp. 61-75.

Lister, M. (2019), “33 mind-boggling Instagram stats \& facts for 2018”, WordStream, https://www.wordstream.com/blog/ws/2017/04/20/instagram-statistics, (accessed 28 October 2020).

Loudenback, T. (2018), “The world's richest people spend \$234 billion a year on luxury goods - here's how much they spend on yachts, private jets, wine, and clothes", Wealth-X, https://www.wealthx.com/about-us/press-news/2018/business-insider-worlds-richestpeople-spend-234-billion-year-luxury-goods-heres-much-spend-yachts-private-jets-wineclothes/, (accessed: 29 October 2020).

Luna- Cortés, G. (2017), “The influence of symbolic consumption on experience value and the use of virtual social networks", Spanish Journal of Marketing, Vol. 21, pp. 39-51.

Lyu, S.O. (2016), “Travel selfies on social media as objectified self-presentation”, Tourism Management, Vol. 54, pp. 185-195.

McCarthy, Nial (2019), “The countries with the most millionaires”, Forbes, https://www.forbes.com/sites/niallmccarthy/2019/10/22/the-countries-with-the-mostmillionaires-infographic/?sh=29b5c81665fa, (accessed 9 November 2020).

McKinsey (2020), “A perspective for the luxury-goods industry during-and after coronavirus", 
https://www.mckinsey.com/ /media/McKinsey/Industries/Retail/Our\%20Insights/A\%20p erspective $\% 20$ for $\% 20$ the $\% 20$ luxury $\% 20$ goods $\% 2$ industry $\% 20$ during $\% 20$ and $\% 20$ after $\%$ 20coronavirus/A-perspective-for-the-luxury-goods-industry-during-and-aftercoronavirus.pdf, (accessed 26 October 2020).

Neate, R. (2020), “The super-rich: another 31,000 people join the ultra-wealthy elite", The Guardian, 4 March, https://www.theguardian.com/news/2020/mar/04/the-super-richanother-31000-people-join-the-ultra-wealthy-elite (accessed 20 October 2020).

Neave, L., Tzemou, E. and Fastoso, F. (2020), "Seeking attention versus seeking approval: how conspicuous consumption differs between grandiose and vulnerable narcissists", Psychology \& Marketing, Vol. 37 No. 3, pp. 418-427.

Nelissen, R.M.A. and Meijers, M.H.C. (2011), "Social benefits of luxury brands as costly signals of wealth and status", Evolution and Human Behavior, Vol. 32 No. 5, pp. 343-355.

Nicolao, L., Irwin, J.R. and Goodman, J.K. (2009), “Happiness for sale: do experiential purchases make consumers happier than material purchases?”, Journal of Consumer Research, Vol. 36 No. 2, pp. 188-198.

Northrop \& Johnson (2020a), "Media use by ultra high net worth individuals 2020”, https://www.northropandjohnson.com/navigator-news/advice/a-study-on-media-use-byultra-high-net-worth-individuals, (accessed 12 November 2020).

Northrop \& Johnshon (2020b), “UHNW luxury market report, 2020”, https://www.northropandjohnson.com/press/luxury-market-report, (accessed 29 October 2020).

O’Cass, A. and McEwen, H. (2004), "Exploring consumer status and conspicuous consumption”, Journal of Consumer Behaviour, Vol. 4 No. 1, pp. 25-39. 
Pantano, E. and Stylos, N. (2020), “The Cinderella moment: exploring consumers' motivations to engage with renting as collaborative luxury consumption mode", Psychology \& Marketing, Vol. 37 No. 5, pp. 740-753.

Patton, M.Q. (2002), Qualitative research and evaluation methods, 3rd ed. Sage, Thousand Oaks, CA.

Parguel, B., Delécolle, T. and Valette-Florence, P. (2016), "How price display influences consumer luxury perceptions", Journal of Business Research, Vol. 69 No. 1, pp. 341-348.

Paul, J. (2015), “Masstige marketing redefined and mapped—introducing a pyramid model and MMS measure", Marketing Intelligence \& Planning, Vol. 33 No. 5, pp. 1-18.

Presi, C., Maehle, N. and Kleppe, I.A. (2016), "Brand selfies: consumer experiences and marketplace conversations", European Journal of Marketing, Vol. 50 No. 9/10, pp. 18141834.

Rosenbaum, M.S., Ramirez, G.C., Campbell, J. and Klaus, P. (2019), "The product is me: hyper-personalized consumer goods as unconventional luxury", Journal of Business Research, https://doi.org/10.1016/j.jbusres.2019.05.017.

Roux, E., Tafani, E. and Vigneron, F. (2017), "Values associated with luxury brand consumption and the role of gender", Journal of Business Research, Vol. 71, pp. 102-113.

Rucker, D.D. and Galinsky, A.D. (2009), “Conspicuous consumption versus utilitarian ideals: how different levels of power shape consumer behavior", Journal of Experimental Social Psychology, Vol. 45 No. 3, pp. 549-555.

Schlenker, B. R., \& Wowra, S. A. (2003), “Carryover effects of feeling socially transparent or impenetrable on strategic self-presentation", Journal of Personality and Social Psychology, Vol. 85 No. 5, pp. 871-880 
Schlosser, A.E. (2020), "Self-disclosure versus self-presentation on social media", Current Opinion in Psychology, Vol. 31, pp. 1-6.

Seidman, G. (2013), "Self-presentation and belonging on Facebook: how personality influences social media use and motivations", Personality and Individual Differences, Vol. 54, pp. 402-407.

Sheldon, P. and Bryant, K. (2016), "Instagram: motives for its use and relationship to narcissism and contextual age", Computers in Human Behavior, Vol. 58, pp. 89-97.

Shukla, P., Singh, J. and Banerjee, M. (2015), "They are not all same: variations in Asian consumers' value perceptions of luxury brands", Marketing Letters, Vol. 26 No. 3, pp. $265-278$.

Sontag, S. (1977), On photography, Picador, New York.

Sorokowska, A., Oleszkiewicz, A., Frackowiak, T., Pisanski, K., Chmiel, A. and Sorokowski, P. (2016), "Selfies and personality: who posts self-portrait photographs?", Personality and Individual Differences, Vol. 90, pp. 119-123.

Spiggle, S. (1994), “Analysis and Interpretation of Qualitative Data in Consumer Research”, Journal of Consumer Research, Vol. 21 no 3, pp. 491-503

Stathopoulou, A. and Balabanis, G. (2019), “The effect of cultural value orientation on consumers' perceptions of luxury value and proclivity for luxury consumption", Journal of Business Research, Vol. 102, pp. 298-312.

Statista (2020a), "Instagram, statistics and facts—-distribution of Instagram users worldwide as of October 2020, by age and gender", https://www.statista.com/statistics/248769/agedistribution-of-worldwide-instagram-users/, (accessed 9 November 2020). 
Statista (2020b), "Luxury goods worldwide",

https://www.statista.com/outlook/21000000/100/luxury-goods/worldwide, (accessed 30

October 2020).

Suri, H. (2011), "Purposeful sampling in qualitative research synthesis", Qualitative Research Journal, Vol. 11 No. 2, pp. 63-75.

Theodoridis, P. and Vassou, S. (2018), "Exploring luxury consumer behaviour”, Berghaus, B., Müller-Stewens, G. and Reinecke, S. (Eds.). The Management of Luxury: A Practitioner's Handbook, Kogan Page Publishers, New York, pp. 75-86.

Thomsen, T.U., Holmqvist, J., von Wallpach, S., Hemetsberger, A. and Belk, R.W. (2020), “Conceptualizing unconventional luxury”, Journal of Business Research, Vol. 116, pp. $441-445$.

Turunen, L.L.M. (2018), Interpretations of luxury. Palgrave Macmillan, London.

Tynan, C., McKechnie, S. and Chhuon, C. (2010), "Co-creating value for luxury brands", Journal of Business Research, Vol. 63, pp. 1156-1163.

Veblen, T. (1899), The theory of the leisure class: an economic study of institutions, MacMillan, New York.

Vigneron, F. and Johnson, L.W. (2004), "Measuring perceptions of brand luxury”, Journal of Brand Management, Vol. 11 No. 6, pp. 484-506.

Wallace, E., Buil, I. and de Chernatony, L. (2020), “Consuming good' on social media: what can conspicuous virtue signaling on Facebook tell us about prosocial and unethical intentions?", Journal of Business Ethics, Vol. 162, pp. 577-592.

Wiedmann, K.P., Hennigs, N. and Siebels, A. (2009), "Value-based segmentation of luxury consumption behavior", Psychology \& Marketing, Vol. 26 No. 7, pp. 625-651. 
